Pero como cada uno de nosotros representamos un papel, ¿dónde está la ilusión? ¿Dónde la realidad?

Esta versión rusa es-hecho curioso-, más sencilla, más comprensible que la versión italiana. Sin embargo, el espíritu latino tiene fama por su claridad, mientras que el espíritu eslavo.... Verdad es que Evreinoff es hijo de una francesa.

En Karl y Anna, Leonardo Franck estudia un caso de desdoblamiento de la personalidad, pero quizá con más sobriedad aún. Dos soldados alemanes están prisioneros en Rusia; el uno está casado, el otro no. Pero este último ha oído hablar tanto de la mujer de su amigo y de su vida antes de la guerra, que la conoce tan bien como él, o quizá mejor. Habiendo logrado evadirse, se hace pasar ante Ana por su esposo. ¿Hasta qué punto se engañan el uno al otro?

Andrés Wurmser estudia a su vez la personalidad en una novela, Cambio de dueño: un hombre se halla de súbito transportado a otro cuerpo, en tanto que ve muerto su antiguo guiñapo. Es la historia de su adaptación a su nueva morada. ¿A quién ha sustituido? Volverse otro, iqué sueño! Pero cambiar de espíritu al mismo tiempo que de cuerpo....-L U I S C H A S S A G N E.

Exclusivo para Alenea en Chile.

\title{
El héroe de la clase media en la novela chilena (1)
}

- $N$ LA SEGUNDA mitad del siglo XIX nace a la vida literaria el héroe de la clase media, Martín Rivas. El propio autor de sus días extensos parece no concederle mayor importancia social. Los comentadores le ven moverse, por entre las páginas, como si fuera un personaje más de la serie blestganiana; un mortal humilde, oscuro, como tantos, que abandona la provincia para tentar fortuna en la capital. Nace en un lejano rincón provinciano, en un país convulsionado por las violencias del torbellino revolucionario y sujeto, como todos los hombres, a las alternativas indóciles del destino. Pero luego se hace comprensible su nacimiento en la voluntad del escritor. La adolescencia del creador de Martín Rivas se nutrió en el firme liberalismo de su padre, el Doctor Blest. El ambiente estaba impregnado

(1) Fragmento del ensayo en preparación Perspectiva de la novela y el cuento chilenos.

Atenea-5 
de doctrinarismo y Bilbao acababa de detener, con un gesto romántico, a la puerta del cementerio, para dar el pase a la inmortalidad, en el nombre de todos los espíritus libres de la monacal y soñolienta capital, al cadáver de Infante, tribuno de las ideas avanzadas de ese tiempo. .

En cierto modo Martín Rivas recogió las aspiraciones y las esperanzas de los espíritus juveniles que se oponían al duro broquel del peluconismo. La época de luchas en que vivió Blest Gana, de tanteos y de heroísmos, de nacimiento de las ideas democráticas, de batallas con la aristocracia conservadora, movieron su pluma para dar vida a ese héroe perseverante, tenaz, modesto, pero lleno de inteligencia, que logra vencer los prejuicios de una casta social y abrir el hermético corazón de una mujer de orgullosa prosapia. Martín Rivas aspiraba a conquistar un puesto en la vida de la capital. Llegaba pobre y ennoblecido por su propia desventura económica y sin más armas que su talento personal. Júzguese la voluntad de que debió estar revestido ese joven humilde que intentaba vencer en una sociedad que acababa de saltar de la colonia al alba de la vida libre, oue estaba aún rodeada de sombras y de orgullos de casta, que era la heredera de los encomenderos y oidores del coloniaje, y que, por tanto, no podía tolerar las explosiones de las fuerzas nuevas, que la emancipación, primero, y las doctrinas liberales, más tarde, habían despertado en el corazón de la juventud. Tropezó con el hermetismo, con el desprecio, en el instante en que olvidó su oscura condición social. El héroe aparecía un poco como el siervo de la encomienda, sin relieve, desconocido, digno de lástima. Más tarde, en la vida y en las novelas, sería el hijo del mayordomo de las haciendas o el estudiante de vida lamentable y difícil, que los padres sostienen con heroicos sacrificios, desde el rincón provinciano o montañés.

\section{EL TRIUNFO DEL HÉROE}

Martín Rivas triunfó en la voluntad del novelista. Venció por el amor, tanto como por sus virtudes. Pero Blest Gana no ignoraba que ese triunfo era un desafío a los prejuicios. Por primera vez un escritor chileno, un novelista, hacía la apología del hombre humilde y lo llevaba después de sucesivos obstáculos y de luchas con el medio, al logro de sus ambiciones. El tipo era una excepción singularísima, colocado en ese medio santiaguino de cerrazón aristocrática, y su triunfo debía constituir un estímulo poderoso para los innumerables soñadores que 
se aprestaban a la lucha por la vida. El procedimiento mismo de Blest Gana para seguir el juego de las pasiones de sus personajes centrales-ya hemos visto cómo intentó proceder a la manera balzaciana - es como el del rumbero de las selvas que tantea las posibilidades para avanzar en la maraña del boscaje. La pasión no brota impetuosa en los corazones puestos en juego. Procede lentamente, con cautela, midiendo cada paso. Es la pasión de la perseverancia, de la tenacidad calculadora. Empieza por un rechazo rotundo de la mujer, para entrar, de seguida, en el camino largo y difícil, a cuyo término clarea el amor. Es justamente el procedimiento más lógico para la época y el mismo que van a seguir, más tarde, los novelistas chilenos que aborden idéntico asunto. Penetración lenta y paciente de una clase social en otra, conquistándola por el amor o por el dinero...

La época de Martín Rivas era simple, un poco romántica. Comunicaciones difíciles; industrias escasas, quietismo comercial. La vida social ceremoniosa, interior, sin efusión para quienes no pertenecían a las tribus de abolengo o de riqueza. Se iba de un punto a otro, en carruajes lentos, devorando caminos polvorientos a lo largo de las haciendas de los poderosos. Las provincias estaban abandonadas a su propia suerte; la existencia, en ellas, vegetativa, monótona, gris, conventual. Como siempre la capital era el centro y la vida, el corazón y el cerebro; la gran aldea, que resumía un poco la inquietud y el goce de vivir, por las compañías de teatros, por las novedades que los veleros traían, a duras penas, desde las costas lejanas de Europa, por los libros de los filósofos y novelistas del viejo mundo. Era el comienzo del afianzamiento; la reorganización después de las luchas terribles de los motines militares. Todavía vagaba, de la capital al puerto de Valparaíso, la sombra trágica y vigilante de Portales. Sobre la tierra del camino aun rojeaba al sol la sangre del ministro omnipotente. En las asambleas políticas y en la prensa comenzaban a entonarse cánticos a las ideas democráticas. Los clubs secretos se llenaban de espíritus jóvenes que voceaban doctrinas de libertad y de justicia social. Entre ellos, un poco separado, casi en un rincón, aparecía la figura melancólica de Martín Rivas.

\section{LA DEFENSA DE LA ARISTOCRACIA.}

Los novelistas posteriores-casi todos ellos de la generación de 1900 -encontraron un ambiente de mayor densidad para el movimiento de sus héroes. Desde luego, la propia vida po- 
lítica había hecho un largo camino de ascensión en el triunfo de las doctrinas democráticas que en 1850 estaban apenas en germen. Subsistía, no obstante, el orgullo de las castas; la defensa de una aristocracia que no quería rendirse a la evidencia de la evolución. Pero habían intervenido otros factores políticos y económicos, inevitables, y el hombre osçuro, sin blasones, el hombre pobre, repechaba rápidamente la cuesta, con sus triunfos a la espalda. Lo mismo en la capital que en las provincias, una clase social nutrida en los encomenderos, en los oidores, en los capitanes de la independencia, en los terratenientes, contenía las audacias del hombre de esfuerzo que aspiraba a fundirse con ella, conquistándola por la riqueza - el talento. La lucha no tenía ya los caracteres de un simple episodio sentimental como en los días románticos de Martín Rivas. Revestía ahora otras formas. En el fondo era una lucha económica.

Crisis profundas abatían a las grandes familias patricias. Las tierras pasaban a manos de los hombres sin abolengo, enriquecidos, a veces mediante matrimonios, en otras, por la simple urgencia de dinero, elaborándose como en un crisol la mezcla y la fusión de las sangres. El desprecio de la aristocracia contra las familias enriquecidas o contra los elementos que se destacaban por su capacidad, era en el fondo el temor a la suplantación, inevitable ya, porque la clase media, por la perseverancia y por el don de la sobriedad, empezaba a llenar todos los sitios de la organización política. En general, las clases aristocráticas han fundado su señorío en la generosidad de las tierras que les pertenecen. Los grandes fundos representan la tradición y el broquel, la sangre y la energía de los grupos sociales de selección. Pero no siempre les era dado a los descendientes mantener el vigor y la constancia de los antepasados.

Los dos instantes de más alta tensión trágica que han hinchado nuestra organización social-la guerra del 79 y la revolución del 91 - provocaron terribles fenómenos de disolución moral: el primero, con la riqueza fabulosa del salitre, dió vida al parvenu ostentoso, desorientó a las familias tradicionales, con el vértigo del lujo y de la frivolidad, provocó las emulaciones perturbadoras, irritó el orgullo de la casta aristocrática que empezaba a ser vencida por la altanera insolencia del rico improvisado, y arrojó en el corazón de la juventud el frenesí del goce materialista. El segundo hizo saltar todos los resortes de la moral, despertó el nido de los instintos, erigió en sistema la deslealtad y la delación, transformó el corazón en un 
avispero de odios, a los hombres en juguete de pasiones innobles, y lo mismo los vencidos que los vencedores convirtieron las luchas políticas en abyectas montoneras.

Estaban ya rotos todos los frenos, y el hombre que debía avanzar sobre las ruinas era el adolescente que no había participado en las luchas fratricidas y que iba a formar en esa clase social media-hijo de campesinos laboriosos, de artesanos sobrios, de comerciantes, de industriales, de profesionalesque componen la gran masa de los maestros, de los intelectuales, de los profesionales, de los comerciantes y agricultores, y que trataría de conquistar los restos de la aristocracia del abolengo o la del dinero. Aristocracias formadas, una en los días lejanos de la colonia o más tarde en el fragor de las luchas; otra en los grandes peculados que nadie sancionó, en las explotaciones afortunadas de la tierra o en las cuantiosas negociaciones salitreras. En todo caso, la aspiración fundamental del hombre modesto, sin fortuna, pero consciente de su capacidad, era vencer a las familias orgullosas cuya descomposición había empezado por el crecimiento rápido de las fortunas y por la competencia que la ostentación había encendido entre la tradición y las familias enricuecidas.

Blest Gana, con su novela Martín Rivas dió origen a una legión de novelistas que plantearon más tarde los conflictos sociales o psicológicos que la aparición del hombre mediócrata provoca en el seno de las familias aristocráticas. Son ellos Daniel Barros Grez, con El huérfano; Luis Orrego Luco, con Un idilio nuevo; Emilio Rodríguez Mendoza, con Cuesta arriba; Juan Barros, con El zapato chino; Fernando Santiván, con El crisol; Augusto Millán, con Desarraigados,-D O M I N G O MELFI.

\section{Crónica de espectáculos}

DESNUDOS ARTÍSTICOS.-CUBANACÁN.-CINE SONORO: EVANGELINA Y LA MELODÍA DE BROADWAY.

- SU PUBICO que concurre a nuestros teatros durante (1) los meses de verano-enteramente diverso del habitual en otras épocas del año-está compuesto casi exclusivamente de hombres, entre los cuales predomina un porcentaje apreciable de maridos en rélache. De aquí que nuestros empresarios se hayan acostumbrado a calcular 